\title{
Special issue on Design, Test, Integration and Packaging of MEMS and MOEMS, 2016
}

\author{
Pascal Nouet $^{1} \cdot{\text { Bernd } \text { Michel }^{2}}^{2}$
}

Published online: 23 December 2017

(C) Springer-Verlag GmbH Germany, part of Springer Nature 2017

The 2016 edition of the symposium on Design, Test, Integration and Packaging of MEMS and MOEMS (DTIP), the premier MEMS scientific annual event in Europe, was held in Budapest, Hungary, May 30-June 2, 2016. DTIP'2016, organized by Prof. Marta Rencz and her team from Budapest University of Technology and Economics was the 18th edition and has been extremely appreciated by an hundred of attendees for the quality of both scientific and social programs. Oral and poster presentations were carefully selected by the Program Committee to insure a high scientific level. This symposium brought together participants interested in manufacturing of microstructures and/or in design tools and methods to facilitate the design of these microstructures.

This special issue is composed of 24 extended versions of the best papers presented at the symposium. Extended papers have been refereed, along the usual refereeing process in force at Microsystem Technologies. Selected papers, out of 33 proposals, cover a broad range of topics including $\mathrm{CAD}$ tools, design methods, multi-physics modelling, thermal evaluation and optimization; test, reliability and failure analysis; sensors and actuators; advances in micro-fabrication, integration and packaging; new materials; advanced characterization techniques.

We hope that you will enjoy these contributions as much as we did and if you want to join the DTIP community don't hesitate to attend our next event or to visit our website.

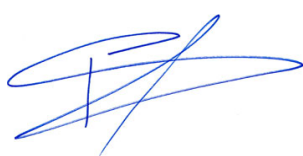

Pascal Nouet

DTIP General Chair

Guest Editor Microsystem Technologies

Bernd Michel

Head of Micro Materials Center

Editor-in-Chief, Microsystem Technologies

Pascal Nouet

dtip@dtip-mems.org

http://www.dtip-mems.org

1 LIRMM, CNRS/University of Montpellier, Montpellier, France

2 Micro Materials Center, Microsystem Technologies, Berlin, Germany 